\title{
Radiological Efficacy of Cervical Lateral Mass Screw Insertion and Rod Fixation by Modified Magerl's Method (Yoon's Method) with Minimum 2 Years of Follow-up
}

\author{
Do Yeon Kim', Ji Yong Kim², Seung Hwan Yoon", \\ Hyung Chun Park ${ }^{1}$, Chong Oon Park ${ }^{1}$ \\ ${ }^{I}$ Department of Neurosurgery, Inha University College of Medicine, Incheon, \\ ${ }^{2}$ Department of Neurosurgery, The Armed Forces Hospital of Pusan, Korea
}

\begin{abstract}
Objective: Cervical lateral mass screw insertion and rod fixation is a useful method for stabilizing the cervical disease, so various modified techniques were present. Many surgeons had reported the biomechanical safety according to the screw positioning method in the cervical spine, but the modified Magerl's method (Yoon's method) was not well studied. So, this study assessed the radiological efficacy of the modified Magerl's method with long-term follow-up.

Methods: This study retrospectively reviewed 323 lateral mass screws of 50 patients who had followed-up at least 2 years. Radiologic data were analyzed as parameters of complications after operation, including kyphotic or lordotic change, bone fusion, pull-out or malposition of screw, foraminal stenosis, adjacent disc degeneration or aggravation, pseudoarthrosis, and vertebral artery injury.

Results: The mean follow-up period was 32 (24 to 52 ) months. There were kyphotic changes in $4.0 \%$ (2 of 50 cases). Unsuccessful bone fusion occurred in $4.0 \%$ (2 of 50 cases). Among the 323 screws, screw pull-out $(4.0 \%$. 2 of 50 cases, 3 of 323 screws), foraminal invasion ( $1.2 \%$ of total screws), and facet injury ( $0.6 \%$ of total screws) occurred.

Conclusion: The lateral mass screw insertion and rod fixation by the modified Magerl's method (Yoon's method) is a safe and reliable technique with low rate of complication related to instruments in minimum 2 years follow-up.
\end{abstract}

Key Words: Spinal fusion $\cdot$ Radiological assessment $\cdot$ Modified Magerl's method $\cdot$ Yoon's method $\cdot$ Long-term follow-up

\section{INTRODUCTION}

Posterior cervical fixation by lateral mass screw insertion and rod fixationhas been frequently used to manage instability caused by trauma, extensive laminectomy state, and destruction by tumors. This technique was first described by RoyCamille et al. ${ }^{21)}$, and several modified techniques of lateral mass screw insertion had been introduced to avoid the related complications. Among them, the most common techniques for lateral mass screw insertion were the Roy-Camille and Magerl's techniques ${ }^{8,14,19)}$. Based on these techniques, new insertion angle techniques for deep screw insertion were modified, and their

- Received: April 13, 2012 - Revised: September 4, 2012

- Accepted: September 26, 2012

Corresponding Author: Seung Hwan Yoon, MD

Department of Neurosurgery, Inha University Hospital, Incheon, Korea

7-206, 3-Ga, Sinheung-dong, Jung-gu, Incheon 400-711, Korea

Tel: +82-32-890-2370, Fax: +82-32-890-2947

Email: nsyoon@gmail.com clinical and radiological safety data had been reported previously. But, Yoon's method, one of the modified Magerl's technique,was not precisely studied in long-term follow-up yet, although it was reported safe method ${ }^{27}$. For this reason, this study assessed the radiological efficacy of the cervical lateral mass screw insertion and rod fixation by Yoon's method with minimum 2 years follow-up.

\section{MATERIALS AND METHODS}

This retrospective analysis study reviewed total 50 consecutive patients who were treated by lateral mass screw insertion and rod fixation between January 2005 and December 2007. The cases presented cover multiple pathologies including 14 cases of fracture/dislocation, 3 cases of spondylosis, 5 cases of ossification of posterior longitudinal ligament (OPLL), 16 cases of cord contusion, and 12 cases of tumors. These all patients were operated on by a surgeon (Yoon SH), and total 323 screws of all patients were treated with the modified 
Magerl's method according to the modified trajectory described by Yoon et $\mathrm{al}^{277}$.

Cervical lateral mass screw insertion and rod fixation was done as usual method of posterior cervical fusion. All patients were taken a prone position with the head hold sligh- tly flexed using three-pin skull fixation. Standard- midline incision was performed and all cervical lateral masses of interest were exposed to facilitate fusion and allow for accurate screw trajectory. The lateral masses were drilled and tapered using the technique of lateral screw insertion trajectories described by a modified Magerl's technique (Yoon's method). The entry point wasinitiated at a point $1 \mathrm{~mm}$ medial and $1 \mathrm{~mm}$ superior to the mid-portion of the lateral mass, and preceded along a course $20-30^{\circ}$ cephalic and about $20^{\circ}$ laterals from C3 to C7. There were 12 cases of transpedicle screw insertion on the thoracic spine due to a C6-7 level injury, but thoracic screws were not included in this study. Afterlateral screw inserted to lesion sites, rods were connected along the screws. Arthrodesis was completed by burring the exposed bone surfaces and placing allobone graft into and around the lateral mass. After surgery, Philadelphia collar was routinely applied to all patients for neck protection and motion limitation to promote the cervical fusion until 6 to 8 weeks after the operation.

Postoperative assessment of lateral mass screw insertion and rod fixation was performed according to the previous study ${ }^{17}$. Routine neurological assessment was performed after surgery. At 1, 6, 12 and 24 months after surgery, routine anterior-posterior and flexion-extension lateral radiographs were obtained for each visit to our clinic, andwe checked the sagittal angle of lateral mass screws on both sides and the presence of screw loosening or breakage. A thin section CT scan focused on the lateral mass fixated area during immediate and last follow-up periods, and the lateral angle of the lateral mass screws on both sides and the position of the screw tip in relation to the vertebral foramen were recorded. The screws with the tip penetrated into the vertebral foramen (foraminal invasion) or into the spinal canal (cord invasion) were defined as mal-position of screw. Cervical lordosis or the instrument level angle were checked by the sagittal cobb's angle between $\mathrm{C} 2$ and C7 (Fig. 1A) or the upper and lower endplate of lateral mass fixated cercvical levels (Fig. 1B) in the neutral cervical lateral radiographies. Cervical or segmental kyphosis of instrument level were defined as more than 10 degrees of the sagittal cobb's angle between $\mathrm{C} 2$ and $\mathrm{C} 7$ or 10 degrees up increment in sagittal cobb's angle between the upper and lower level of lateral mass fixated levels. In this study, the criterion for fusion is the presence of bony trabecular continuity between the vertebral bodies, and non-union was defined as a visible gap, graft collapse, and motion of greater than $5^{\circ}$ with dynamic radiographies.

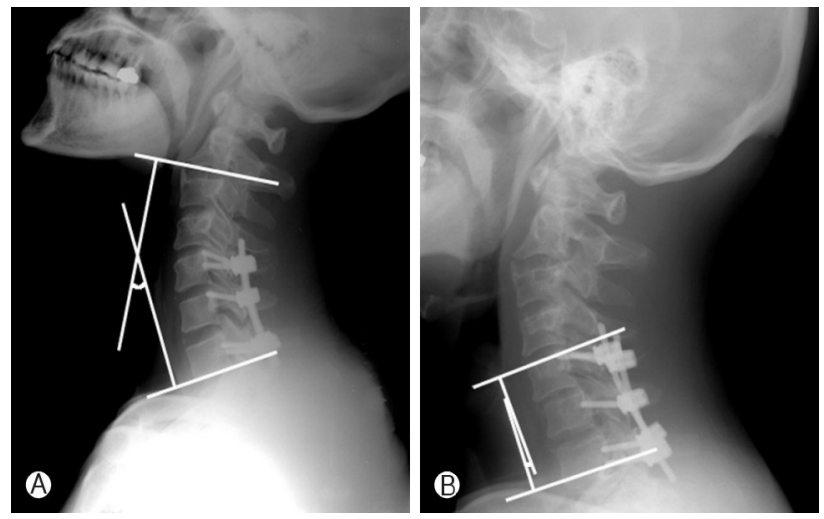

Fig. 1. The angle of C2-C7 (A) and upper-lower in lateral mass insertion (B) was obtained to compare the stability between immediate postoperative and last follow-up lateral $\mathrm{x}$-rays.

Table 1. Comparison of cobb's angle between pre- and post-operation

\begin{tabular}{lccl}
\hline \hline & $\begin{array}{c}\text { Pre- } \\
\text { operation }\end{array}$ & $\begin{array}{c}\text { Post- } \\
\text { operation }\end{array}$ & p-value \\
\hline Stability & & & \\
C2-C7 angle & $18.81 \pm 10.72^{\circ}$ & $14.76 \pm 8.47^{\circ}$ & 0.000 \\
$\quad$ Instrument level angle & $7.01 \pm 4.38^{\circ}$ & $6.99 \pm 2.80^{\circ}$ & $\mathrm{N}-\mathrm{S}$ \\
Flexibility & & & \\
$\quad$ Proximal kyphosis & $4.00 \pm 2.29^{\circ}$ & $5.91 \pm 3.17^{\circ}$ & 0.000 \\
$\quad$ Distal kyphosis & $3.17 \pm 2.89^{\circ}$ & $4.45 \pm 2.84^{\circ}$ & 0.000 \\
\hline
\end{tabular}

*Post-operation image was checked in 24 months after the operation.

\section{RESULTS}

Total 50 patients (40 males and 10 females) were includedin this study. The age of patients at the time of operation ran ged from 16 to 80 years (mean 52 years). Mean follow-up period was 32 months (range 24 months to 52 months). There were no statistically difference between the surgical levels, composition of cervical disease, and sizes of cervical lateral masses of lesions by the age or sex of patients. Also, no neurologically deterioration was observed during the follow-up period. All patients were stabilized with screws and rods, and total screw cases were 323 screws implanted in 50 patients.

Cervical lordosis and segmental angle of instrument levels were summarized in Table 1 . Cervical lordosis by cobb angle between C7 and C7 was $18.81 \pm 10.72^{\circ}$ in immediate post-operated status, and it significantly increased to $14.76 \pm 8.47^{\circ}$ in 24 months follow-up $(\mathrm{p}<0.001)$. The instrument level cobb angle was not significantly change in immediate post-operated and 24 months follow-up status $\left(7.01 \pm 4.38^{\circ}, 6.99 \pm 2.80^{\circ}\right.$, respec- 


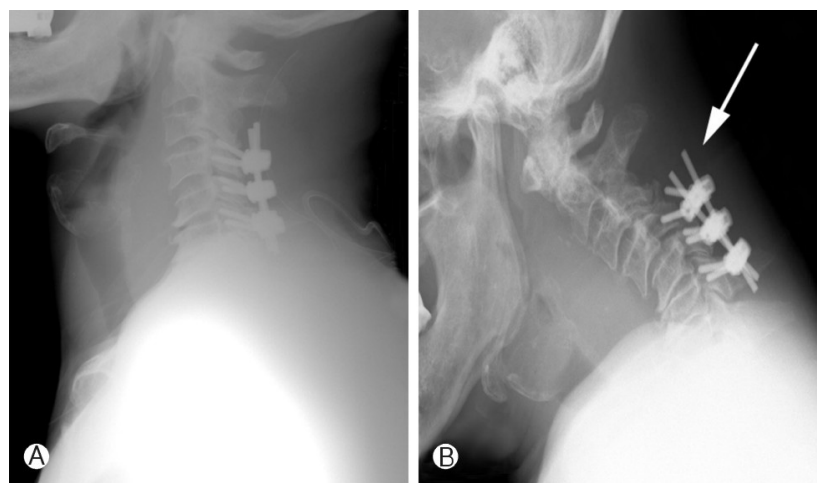

Fig. 2. Immediately after operation (A), the screws were well-posi tioned. Flexion lateral cervical spine radiographs (B) showing a pulled-out proximal screw (arrow).

tively). Flexibilities checked by proximal and distal kyphosis were markedly increased from immediate operated status to follow-up. Proximal kyphosis was increased from $4.00 \pm 2.29^{\circ}$ to $5.91 \pm 3.17^{\circ}(\mathrm{p}<0.001)$, and distal kyphosos was increased from $3.17 \pm 2.89^{\circ}$ to $4.45 \pm 2.84^{\circ}$ ( $\mathrm{p}<0.001$ ). Junctional kyphosis between immediate postoperative and last follow- up lateral x-ray was observed in $4.0 \%$ (2 of 50 cases) including one case with non-fusion. Unsuccessful bone fusion occurred in $4.0 \%$ ( 2 of 50 cases), but did not need further operation.

Among the 323 screws, screw pull-out was observed in 2 patients (4.0\%) with $0.9 \%$ of case by screw rate (3 of 323 screws) (Fig. 2), foramen invasion without definite vertebral artery injury was exhibited in $1.2 \%$ (4 of 323 screws) (Fig. 3). The radiographs revealed facet injury occurred in $2 \mathrm{pa}-$ tients (0.6\%) (Fig. 4). One patient experienced screw pull-out, foraminal stenosis, and aggra- vation of adjacent disc protrusion simultaneously. Other complications suchas pseudoarthrosis and vertebral artery injury were not observed during this follow-up.

\section{DISCUSSION}

Since Roy-Camille first introduced cervical lateral mass screw fixation in $1979^{21)}$, many modified techniques for screw insertion, including Magerl, Anderson, An, and Yoon have been published in an effort to reduce the risk of neurovascular and facet injury $3,4,6,7,9,10,11,14,24,27)$. Previously introduced lateral mass screwingmethods have reported some neurovascular complications related to the trajectory of screw. Heller et al. reported that biomechanical limitations of lateral mass screwing came from the small amount of bonypurchase availability such as screw loosening or avulsion ${ }^{12,13)}$. Currently, many researchers have introduced a modifiedtrajectory of the lateral mass screw to supplement the limitation of this method.

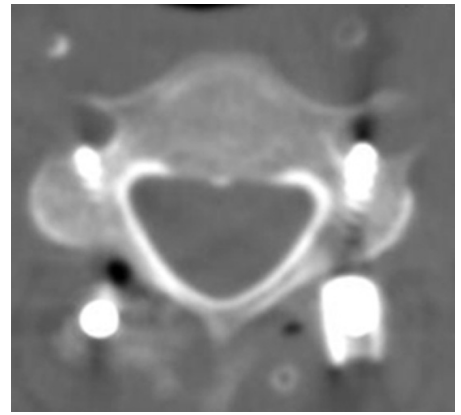

Fig. 3. An axial image of a CT scan showing a screw which pro- truded into the ver- tebral foramen without vascular penetration. Further operation was not necessary.

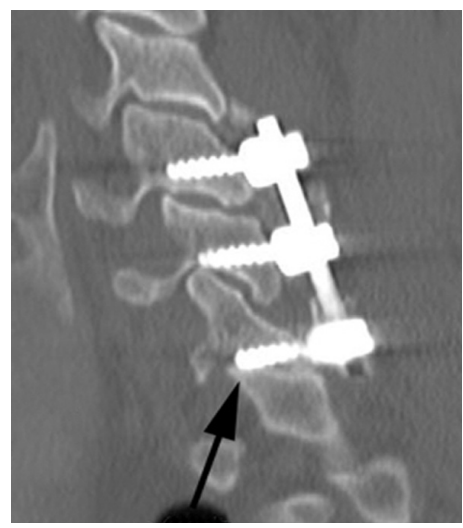

Fig. 4. A sagittal section of a CT scan showing the malposition of a lateral mass screw, which violated the adjacent facet (arrow).

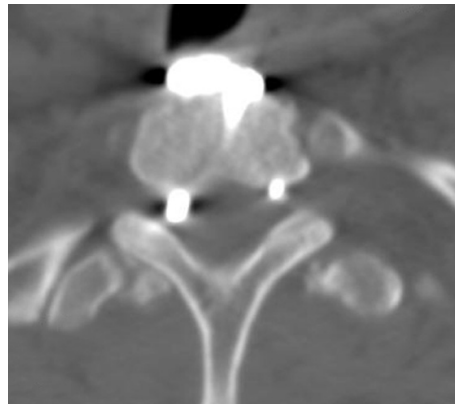

Fig. 5. An oxial CT scan showing a screw which deviated toward the medial wall in the thoracic spine.

Heller et al. reported the result of 654 screws inserted in 78 patients ${ }^{12}$. Complication rates as a function of the number of inserted screws which included nerve root injury, facet violations, vertebral artery injury, broken screw, screw avulsion, and screw looseningwere below 1.1\%. Lali reported that the complication rate was $0.7 \% \%^{22)}$.

The authors had introduced a modified lateral mass screwing method, a reduced sagittal $\left(43.9 \pm 4.5^{\circ}\right)$, and a lateral angle of screw $\left(19.6 \pm 3.5^{\circ}\right)$ performed with a concept based on Magerl's method which resulted in a deeper depth of the screw $(13.5 \pm 2.1 \mathrm{~mm})^{27)}$. The principle of this technique involved deeper insertion of screws safely while avoiding cord or root violation. This modified from Magerl's technique ascertained evidence that our consecutive lateral mass screwing method was safe and efficient. In 50 patients, 323 lateral mass screws were inserted. The mean follow-up period was 32 (24 
to 52 ) months. There were kyphotic changes in $4.0 \%$ (2 of 50 cases) and among 323 screws, screw pull-out (4\% of 50 cases or $0.9 \%$ of total screws), foraminal invasion (1.2\% of total screws), and facet injury ( $0.6 \%$ of total screws) occurred. There was no vertebral artery injury on postoperative CT scan or screw loosening on dynamic x-ray follow up. This study showed that lateralmass fixation is a safe and reliable method of posterior stabilization with a modified trajectory of the lateral mass screw.

Junctional kyphosis related to the thoracolumbar spinal fusion has been considered a major drawback and has been reported in several studies, ${ }^{5,16,25}$. However, even though there is a long level fusion, posterior lateral mass screw fixation of the cervical spine has a lower rate of junctional problem than that of th elumbar spine. Heller et al. reported that the adjacent segment degeneration after cervical lateral mass screw fixation was $3.8 \%{ }^{13)}$, and Lali described the occurrence of adjacent segment degeneration as one in 143 patients $(0.6 \%)^{22)}$. In the current series, we found that junctional problems in cervical lateral mass fixation occurred at a rate of $4.0 \%$. The main cause of this may be lower motion of the upper-lower lateral mass screw on the cervical spine than that on the lumbar spine or lower weight of loading on the cervical spine than on the lumbar spine.

Actually, the modern posterior cervical stabilizing techniques was divided into pedicle screw fixation and lateral mass screw fixation. Pedicle screw fixation of the cervical spine has been considered as an effective procedure for stabilizing unstable spine injury ${ }^{1)}$. Most researchers report a high success rate of stabilization of the cervical spine after pedicle screw fixation however, it also has the potential to injurethe nerve root or vertebral artery and there is a high mal-position rate of screw and therefore, the safety of this technique is still in doubt $^{20,26}$. Abumi et al. reported complications of cervical pedicle screw fixation. For example, the pedicle perforation rate was $6.2 \%$ (45 out of 667 screws) and neurovascular complications occurred in two screws. Yoshimoto et al., Yukawa et al., and Kasts et al. reported the pedicle perforation rates were $11.1 \%$ (15 out of 134 screws), $14.3 \%$ (59 out of 417 screws), and 30\% (28 out of 94 screws), respectively, including eight screws with critical breaching ${ }^{2,15,28,29)}$.

Lateral mass screw fixation of cervical spine also provides an effective bone fusion for stabilizing unstable spinal injury compared to pedicle screw fixation. Wang et al. evaluated the the fusion rate of $\mathrm{C} 1$ lateral mass and $\mathrm{C} 2$ pedicle screws ${ }^{23}$. They concluded that bone fusion be- tween $\mathrm{C} 1$ lateral mass and C2 pedicle screws were achieved in all 319 cases (100\%). Liu et al. reported that 38 consecutive patients with symptomatic anterior cervical pseudarthrosis were managed successfully with posterior lateral mass screw fixation and fusion $(100 \%)^{18)}$.
In our study, kyphosis and/or unsuccessful bone fusion occurred in $6.0 \%$ (3 of 50 cases), but did not need further operation. Further, the rate of screw pull-outs was $4.0 \%$ ( 2 of 50 cases, 3 of the 323 screws). Lateral mass screws may be considered a safe and efficient method for stabilization because this method shows a relatively lower complication rate than pedicle screw fixation and there is not much difference between the two with respect to the rate of bone fusion or screw failure (biomechanical stability).

We believe that this study has not provided a newer technique for lateral mass screwing as compared to previous method. Rather, our technique is more safe and efficient than those previous. This study was a retrospective report based on a patient's medical record. Therefore, it should include followup on both clinical and anatomical bases using cadavers for comparison in future studies.

\section{CONCLUSION}

The lateral mass screw insertion and rod fixation by the modified Magerl's method (Yoon's method) is a safe and reliable technique with low rate of complication related to instruments in minimum 2 years follow-up.

\section{ACKNOWLEDGEMENT}

The authors thank to Chang Hyun Oh, M.D., a fellow in the department of Neurosurgery, Inha University Hospital, who reviewed and revised this article in the revise status. This article has no conflict of interest, and no financial support.

\section{REFERENCES}

1. Abumi K, Itoh H, Taneichi H, Kaneda K: Transpedicular screw fixation for traumatic lesions of the middle and lower cervical spine: description of the techniques and preliminaryreport. J Spinal Disord 7:19-28, 1994

2. Abumi K, Shono Y, Ito M, Taneichi H, Kotani Y, Kaneda K: Complications of pedicle screw fixation in reconstructive surgery of the cervical spine. Spine (Phila Pa 1976) 25:962-969, 2000

3. An HS, Gordin R, Renner K: Anatomic considerations for platescrew fixation of the cervical spine. Spine (Phila Pa 1976) 16: S548-551, 1991

4. Anderson PA, Henley MB, Grady MS, Montesano PX, Winn HR: Posterior cervical arthrodesis with AO reconstruction plates and bone graft. Spine (Phila Pa 1976) 16:S72-79, 1991

5. Casey MP, Asher MA, Jacobs RR, Orrick JM: The effect of Harrington rod contouring on lumbar lordosis. Spine (Phila Pa 1976) 12:750-753, 1987

6. Cho JI, Kim DH: Comparative analysis of cervical lateral mass 
screw insertion amongthree techniques in the Korean population by quantitative measurements with reformatted 2D CT scan images: clinical research. J Korean Neurosurg Soc 44:124-130, 2008

7. Choi HJ, Kim KS, Park KS, Han IH, Chin DK, Jin BH, et al: Technical stragies and surgical results of C1 latermall mass-C2 pedicular screw fixation in atlantoaxial disorders. Korean $\mathrm{J}$ Spine 5:196-202, 2008

8. DalCanto RA, Lieberman I, Inceoglu S, Kayanja M, Ferrara L: Biomechanical comparison of transarticular facet screws to lateral mass plates in two-level instrumentations of the cervical spine. Spine (Phila Pa 1976) 30:897-902, 2005

9. Ebraheim NA, Hoeflinger MJ, Salpertro B, Chung SY, Jackson WT: Anatomic considerations in posterior plating of the cervical spine. J Orhop Trauma 5:196-199, 1991

10. Ebraheim NA, Xu R, Stanescu S, Yeasting RA: Anatomic relationship of the cervical nerves to the lateral masses. Am J Orthop 28:39-42, 1999

11. Heller JG, Carlson GD, Abitbol JJ, Garfin SR: Anatomic comparison of the Roy-Camille and Magerl techniques for screw placement in the lower cervical spine. Spine (Phila Pa 1976) 16:S552-557, 1991

12. Heller JG, Estes BT, Zaouali M, Diop A: Biomechanical study of screws in the lateral masses: variables affecting pull-out resistance. J Bone Joint Surg Am 78:1315-1321, 1996

13. Heller JG, Silcox DH $3^{\text {rd }}$, Sutterlin CE $3^{\text {rd }}$ : Complications of posterior cervical plating. Spine (Phila Pa 1976) 20:2442-2448, 1995

14. Jeanneret B, Margerl F, Ward EH, Ward JC: Posterior stabilization of the cervical spinewith hook plates. Spine (Phila Pa 1976) 16:S56-63, 1991

15. Kast E, Mohr K, Richter HP, Börm W: Complications of transpedicular screw fixation in the cervical spine. Eur Spine J 15 : 327-334, 2006

16. La Grone MO: Loss of lumbar lordosis. A complication of spinal fusion for scoliosis. Orthop Clin North Am 19:383-393, 1988

17. Lee DC, Yoon SH, Park HC, Park JO, Hyun DK, Park HS: Clinical and computed tomography evaluation of plate and screw on the cervical lateral mass: a modified Margerl's technique. J Korean Neurosurg Soc 39:251-255, 2006
18. Liu H, Ploumis A, Schwender JD, Garvey TA: Posterior cervical lateral mass screw fixation and fusion to treat pseudoarthrosis of anterior cervical fusion. J Spinal Disord Tech 25:138141, 2012

19. Roy-Camille R: Methods of osteosynthesis with posterior screw plates. Chicago: Yearbook pp373-376, 1989

20. Roy-Camille R: Rationale and techniques of internal fixation in trauma of the cervical spine. Philadelphia: JB Lippincott pp163-191, 1991

21. Roy-Camille R, Gaillant G, Bertreaux D: Early management of spinal injuries. Edinburgh: Churchill-Livingstone pp57-87, 1979

22. Sekhon LH: Posterior cervical lateral mass screw fixation Analysis of 1026 consecutive screws in 143 patients. J Spinal Disord Tech 18:297-303, 2005

23. Wang S, Wang C, Wood KB, Yan M, Zhou H: Radiographic evaluation of the technique for $\mathrm{C} 1$ lateral mass and $\mathrm{C} 2$ pedicle screw fixation in three hundred nineteen cases. Spine (Phila Pa 1976) 36:3-8, 2011

24. Xu R, Haman SP, Ebraheim NA, Yeasting RA: The anatomic relation of lateral mass screws to the spinal nerves. A comparison of the Magerl, Anderson, and An technique. Spine (Phila Pa 1976) 24:2057-2061, 1999

25. Yang SH, Chen PQ: Proximal kyphosis after short posterior fusion for thoracolumbar scoliosis. Clin Orthop Relat Res 411:152-158, 2003

26. Yukawa Y, Kato F, Ito K, Horie Y, Hida T, Nakashima H, et al: Placement and complications of cervical pedicle screws in 144 cervical trauma patients using pedicle axis view techniques by fluoroscope. Eur Spine 18:1293-1299, 2009

27. Yoon SH, Park HC, Park HS, Kim EY, Ha Y, Chong CK, et al: Radiological considerations of posterior cervical lateral mass fixation using plate and screw. Yonsei Med J 45:406-412, 2004

28. Yoshimoto H, Sato S, Hyakumachi T, Yanagibashi Y, Masuda T: Spinal reconstruction using a cervical pedicle screw system. Clin Orthop Relat Res 431:111-119, 2005

29. Yukawa Y, Kato F, Yoshihara H, Yanase M, Ito K: Cervical pedicle screw fixation in 100 cases of unstable cervical injuries: pedicle axis views obtained using fluoroscopy. J Neurosurg Spine 5: 488-493, 2006 